\title{
CADÊ O TEMPO QUE ESTAVA AQUI?: REFLEXÕES SOBRE AS CONCEPÇÕES DE TEMPO ANTES E DURANTE A SOCIEDADE DA INFORMAÇÃO
}

\begin{abstract}
Resumo: Neste ensaio, aborda-se conceitos sobre a sociedade atual, chamada de informacional por Castells (2006) e de modernidade líquida por Bauman (2001). Relaciona as percepções das pessoas com o tempo em seus momentos de lazer e como estão próximos da informação, em uma comparação com o período anterior à sociedade da informação. Divide-se em duas partes, a primeira resgata em estudos históricos a relação das pessoas com o tempo desde a Idade Média; a segunda parte apresenta relações atuais de como as pessoas lidam com a tecnologia e a informação e como se sentem quanto ao passar do tempo. Ao longo dos anos as rotinas das pessoas se alteraram, logo seus sentimentos quanto ao tempo disponível diante do excesso de informação a que estamos submetidos.
\end{abstract}

Palavras-chave: Sociedade da informação. Comportamento informacional. Tempo.

\author{
Marcela Reinhardt de Souza \\ Mestra em Ciência da Informação \\ pela Universidade Federal de \\ Santa Catarina (UFSC), \\ Santa Catarina - SC, Brasil. \\ marcelareinhardt@yahoo.com.br
}

\section{WHERE WAS THE TIME THAT WAS HERE?: REFLECTIONS ON TIME CONCEPTIONS BEFORE AND DURING THE INFORMATION SOCIET}

\begin{abstract}
This essay addresses concepts about the current society, called informational by Castells (2006) and liquid modernity by Bauman (2001). It relates people's perceptions of time in their leisure time and how close they are to information, in comparison with the period prior to the information society. It is divided into two parts, the first rescues in historical studies the relationship of people with time since the Middle Ages; the second part presents current relationships on how people deal with technology and information and how they feel about time. Over the years people's routines have changed, so their feelings about the time available in the face of the excess of information to which we are submitted.
\end{abstract}

Keywords: Information society. Informational behavior. Time. 


\section{INTRODUÇÃO}

Seja em uma mesa de bar, no escritório, na fila do mercado, na sala de aula ou em um jantar em família, um desabafo é recorrente: “o tempo está passando rápido demais". A sensação de que o tempo hoje passa mais rápido do que antes é compartilhada entre as pessoas. Vivemos em um mundo volátil, repletos de afazeres que sobrecarregam nossas horas e vivemos lutando para dar conta de todos os compromissos e ainda encontrar algum tempo para respirar e ter momentos de lazer.

Mario Quintana (2013, p. 38) disse “Quando se vê, já são 6 horas: há tempo... / Quando se vê, já é 6a-feira... / Quando se vê, passaram 60 anos...”. A sensação de o tempo correr mais do que se vê não é desafio apenas da atualidade, mas com isso pode-se trazer o seguinte questionamento: qual a relação entre a sensação quanto ao passar do tempo e a sociedade da informação? O profundo mergulho no mundo informacional pode fazer com que sobre menos tempo livre, podendo trazer a sensação do passar mais rápido do tempo. Ou seria essa uma questão do ser humano desde os tempos mais remotos?

Sobre o período atual em que vivemos, serão abordados Castells e Bauman, que buscaram debater sobre a sociedade, seus conceitos, características e diferenças com períodos anteriores. De acordo com Castells (2006, p. 142) a informação tornou-se produto do processo produtivo, o que fez esta sociedade diferente dos demais momentos históricos, devido a apoiar-se em um "paradigma tecnológico baseado em tecnologias da informação". Bauman (2001) defende que a sociedade atual, ao contrário de um período anterior mais sólido, pode ser considerada líquida, a qual o consumismo não diz respeito às questões de satisfação de necessidades básicas, mas está vinculado ao desejo - volátil e efêmero - substituído pelo simples querer. Queremos que o mundo atenda aos nossos desejos e seja do modo como sonhamos e que o tempo corresponda na mesma medida a qual decidimos que deve sê-lo. Neste sentido, observa-se uma grande decepção, visto que isso é inviável.

Castells (2006, p. 119, grifo do autor) nos explica que a sociedade a qual vivemos tem três características principais e se relaciona com a forma como a economia está apoiada, informacional, global e em rede:

É informacional porque a produtividade e a competitividade de unidades ou agentes nessa economia (sejam empresas, regiões ou nações) dependem basicamente se sua capacidade de gerar, processar e aplicar de forma 
eficiente a informação baseada em conhecimentos. É global porque as principais atividades produtivas, o consumo e a circulação, assim como seus componentes (capital, trabalho, matéria-prima, administração, informação, tecnologia e mercados) estão organizados em escala global, diretamente ou mediante uma rede de conexões entre agentes econômicos. É rede porque, as novas condições históricas, a produtividade é gerada, e a concorrência é feita em uma rede global de interação entre redes empresariais.

O modo como estamos próximos da tecnologia nos faz vivenciar uma realidade a qual estamos submersos na informação, sobrecarregados dela e correndo sem saber para onde, sem saber se há opções de escape e podendo até adoecer nesta busca. O comportamento das pessoas diante da informação mudou, porque a sociedade e a tecnologia mudaram e a adaptação pode nem sempre ser saudável para todos. É positiva a possibilidade de acesso à informação que temos disponível, a questão apresenta-se apenas em como esta informação transforma e influencia a nossa saúde.

Ao pensarmos sobre como as pessoas lidam com a informação atualmente e relacionála com a tecnologia, é destacável a diferença no comportamento informacional, ou seja, no modo como as pessoas buscam e lidam com a informação, hoje diferente de antes da existência dos smartphones e do aumento de possibilidades para conexão com a internet. Como consequência, o modo o qual as pessoas ocupam seus dias também sofreu alterações.

\section{A OS ANOS DE ONTEM}

Quando se acredita que ontem o tempo passava mais lentamente, remete-se a uma época a qual as vidas eram mais vividas em comunhão com o tédio. Um mês parecia lentamente seguir-se dentro de anos. O que se pode questionar é se esta sensação sempre existiu ou se está mais presente atualmente. Se é fruto do saudosismo do tempo passado ou se refere às nossas rotinas cada vez mais agitadas.

Batista et al (2013) descreveu que até a Revolução Industrial o tempo exercia menos poder na vida das pessoas. Assim, as mudanças socioculturais trouxeram novas formas de percepção do tempo. Os autores afirmam que o cotidiano ficou cronometrado, os relógios passaram a fazer parte da vida e até mesmo as atividades começaram a ser ditadas pela necessidade de regulação. Leccardi (2005, p. 39) aponta que os seres humanos primitivos não percebiam a mudança do tempo como ruptura e descontinuidade, ou seja, sem diferenciar o futuro e o passado por este ângulo, há uma visão diferente de tempo: 
São os ritmos da natureza, a sucessão das estações e os ritmos produtivos que aqueles cadenciam que constituem os parâmetros temporais sociais. $\mathrm{O}$ tempo, aqui, não é separado da ação ou de seus conteúdos: falta, em outros termos, qualquer conotação do tempo como entidade abstrata e quantificável.

Desta maneira, os parâmetros temporais sociais, estavam conectados com a própria natureza e não com uma criação humana de tempo. Mas sim, com as épocas relacionadas aos ritmos da natureza, com o suceder de sol e da chuva, da noite e do dia e assim por diante. $\mathrm{O}$ tempo é visto como algo contínuo, sem as rupturas hoje existentes, como anos e horas.

Assim, percebe-se que as concepções de tempo se alteraram. Em qualquer conversa as pessoas tendem a acreditar que o tempo sempre passa mais depressa. Os historiadores já se ocuparam de pesquisas sobre essa questão e a seguir serão apresentadas algumas das conclusões chegadas por eles. Iniciamos por Le Goff (1993), historiador que dedicou seu trabalho a estudar o período medieval. O autor defendeu que durante o período da Idade Média existiam dois tempos distintos, ou seja, a concepção de tempo dividia-se entre aquela considerada o tempo da igreja - dos teólogos e filósofos cristãos - e o tempo do mercador mais pragmático. O primeiro mais voltado às horas canônicas e o segundo às horas práticas do trabalho comercial e visto como objeto de medida. Assim, tem-se que "mercadores e artífices substituem este tempo da Igreja pelo tempo mais exactamente medido, utilizável para as tarefas profanas e laicas, o tempo dos relógios" (LE GOFF, 1993, p. 53). O autor aponta que além dos sinos das igrejas, surgem as torres com relógios para marcar o tempo e este, antes pertencente a Deus e não passível de venda, passa a pertencer aos homens.

Rust (2008, p. 4) complementa que "os mercadores exteriorizavam o tempo para submetê-lo a um agir estratégico e instrumental, para convertê-lo em uma modalidade de monitoramento de tarefas e da produtividade”. É possível perceber semelhanças no modo como vemos o tempo, muito mais próxima da visão dos mercadores do que da igreja. O autor interpreta que estes tempos estudados por Le Goff (1993) se dividiam entre "um tempo agrário versus um tempo urbano" (RUST, 2008, p. 4). O tempo dos mercadores se sobrepôs ao da igreja quando as mudanças determinaram as características que fizeram da próxima fatia do tempo histórico, intitulado hoje de Idade Moderna.

O modo de observar a passagem do tempo pelos nossos olhos se alterou ao longo dos anos. No entanto, há de se ter cuidado com as idealizações sobre o passado para não 
recorrermos ao equívoco de crer nos bons tempos antigos como melhores do que o momento atual. Segundo Maffesoli (2006, p. 278), às vezes pode ocorrer de ao pensarmos no passado, o vermos como tempos melhores, mas de fato "não passa de uma miragem, uma ilusão, um simulacro".

Há diferenças também no que trata do tempo histórico e da concepção de tempo das pessoas. Asad (2017) exemplifica questões pontuais sobre o Egito contemporâneo e nota que em determinadas circunstâncias o tempo é concebido como ligando o passado, o presente e o futuro, diferentemente do tempo linear e do tempo histórico. Ainda que seja uma observação pontual sobre um local, traz contribuições para este debate, uma vez que nos deixa claro a relatividade do tempo, dependendo da situação, do local, do período o qual ele é pensado. Neste sentido, Leccardi (2005, p. 37) nos conduz ao pensamento de que "quanto mais as sociedades se diferenciam, mais os conceitos temporais tendem à abstração, a um grau mais elevado de síntese conceitual", o tempo é visto como dimensão social. Ainda para a autora (2005, p. 38) a ideia moderna de futuro nasceu entre os séculos XVII e XVIII, em que:

[...] o futuro torna-se o novo centro da práxis humana, a aposta, o risco e o desafio com os quais é necessário defrontar-se. Pela primeira vez, com a modernidade, perdem a eficácia instâncias extra-históricas às quais se possa imputar sua criação. O futuro depende inteiramente do agir dos sujeitos; o mesmo acontece com a história. Ambos são construídos e projetados.

O tempo futuro, considerado como uma projeção humana, passa a existir no imaginário ampliando os conceitos temporais, trazendo para o presente as ideias de planejamento para um tempo que está por vir. Um tempo determinado pelos humanos, diretamente ligado aos dias e anos pré-estipulados na, até então, nova contagem.

Partindo para a literatura durante a Europa feudal, tem-se Régnier-Bohler (2004). A autora apresenta que um início da tomada de consciência acerca do tempo pode ser observado na literatura dos séculos XIII e XIV. Um dos exemplos citados é do poeta do século XIII, Rutebelf, o qual escreveu sobre o passar do tempo e dos amigos que com ele desapareciam. Realidade observada também atualmente, em que o tempo pode ser utilizado com desculpa para a dificuldade em encontrar os amigos.

Outro exemplo trazido pela autora supracitada é de Eustache Deschamps, poeta francês do século XIV, que: 
parece ter sido particularmente obsedado pela instabilidade e pela fragilidade, pela velhice e pela vanidade das coisas humanas, pela percepção do 'ciclo da vida, à imagem do relógio que se acaba de inventar' (RÉGNIER-BOHLER, 2004, p. 378).

As percepções sobre o tempo da própria existência humana ou individual, foram alteradas depois da criação do relógio, porque passaram as ser contabilizados e estimados. Com isso, além da nova percepção de existência de um futuro datado, tem-se também a ideia de uma vida entendida por ciclos com possíveis datas limites para o fim.

Trazendo a discussão para tempos mais recentes, chega-se na década de 1990. Neste momento Body-Gendrot (1992) observava que a falta de tempo poderia ser relacionada até com uma questão de orgulho pessoal para alguns. A autora acredita que na França, exceto para os membros das classes dominantes, era considerado bonito dizer que está ocupado e mencionar os diversos encontros que se tem agendado e ainda chegar atrasado em jantares, não responder as correspondências nem retornar recados. Body-Gendrot (1992) compara os franceses com os estadunidenses. Os últimos ensinam administração do tempo desde o Ensino Médio e educam as pessoas para a eficácia, para atingir os objetivos no menor tempo possível, vivendo um presente projetado para o futuro. Assim, surgiu a tecnologia, prometendo reduzir o tempo das tarefas às pessoas de modo que nos fez chegar aos dias que vivemos hoje.

Não se viveu em séculos anteriores um momento em que a informação recebia tamanha importância na economia. De modo geral, acessar a informação não ocupava parte do tempo das pessoas, podendo trazer diferentes relações com o passar dos anos. As rotinas eram diferentes em anos anteriores ao que é hoje e são os dias atuais que serão abordados na próxima seção.

\section{AS HORAS DE HOJE}

Quando se acredita que hoje o tempo passa mais rápido, remete-se ao momento atual em que as horas passam diante de nossos olhos enquanto sobra a sensação de ter feito pouco. Um mês parece correr dentro de poucas horas.

Pode-se perceber a relação das pessoas com o tempo como um projeto. Mattelart (2005) apontou que a intelectualização do trabalho e do consumo tem a contribuir com o alinhamento dos produtores de informação e conhecimento em prol de dinâmicas dominantes. 
A vivência atual que sobrecarrega e faz lutar contra o tempo, uma luta perdida desde o início, faz parte desse projeto de sociedade liderada pelos países capitalistas ao tornar as pessoas em máquinas reprodutoras e não pensantes. Werthein (2000) mostrava-se preocupado com o sentimento visível de perda de controle da própria vida e perda de identidade na sociedade da informação e sinalizava a necessidade de estratégias para intervir neste sentido.

Observa-se expressões claras da necessidade de mudança de rumos os quais tempos atuais se direcionam a partir de movimentos como o Cittaslow e o Slow movement. Esses movimentos de Slow, "sugerem formas de combater o tempo rápido, o qual é próprio da contemporaneidade" (BATISTA et al., 2013, p. 34). Já que o ritmo atual da sociedade leva as pessoas à fast life (vida rápida), ditada pela produtividade representada em grande parte das cidades capitalistas do planeta, tornando o ser humano desconectado de sua natureza e ritmo biológico (CARVALHO, 2015).

Uma proposta de fuga dessa realidade quase inevitável, é o movimento intitulado Cittaslow (movimento das cidades lentas), com a ideia de propor um ritmo mais lento para as cidades e práticas cotidianas das pessoas, propondo difundir uma cidade para se viver bem, investindo em qualidade de vida (CARVALHO, 2015). Neste sentido, Batista et al. (2013, p. 30) cita o Slow movement "movimento mundial em prol da desaceleração" que "contribui para apaziguar os sofrimentos psíquicos causados pela pressão do tempo, mas não para a sua revolução".

Esses movimentos são reflexos de como as algumas pessoas podem se sentir oprimidas pela sociedade da informação, na qual observa-se constante sobrecarga de informação. Este conceito não é novidade, Bawden, Holtham e Courtney (1999) consideram que a sobrecarga de informação passou a ser identificada como um problema a partir dos anos de 1950 e 1960, com o aumento exponencial de publicações. Já no ambiente do trabalho, os autores destacam que nos anos de 1990 foi identificado o sentimento de sobrecarga por parte dos profissionais e com isso, ocorriam perdas e insatisfação no trabalho. Embora seja considerado que pelo menos desde 1755 há apontamentos quanto à dificuldade em lidar com a quantidade de informação disponível, ou seja, configura-se um problema histórico e nada recente (JOHNSON, 2012).

Uma vez que a sociedade da informação está diretamente relacionada a forma como a informação é considerada pelos sistemas econômicos (CASTELLS, 2006), é possível observar que o capitalismo mudou a visão sobre o tempo e definiu que: 
Tempo é dinheiro e, dessa forma, desempenha papel decisivo no capitalismo, de modo que a exploração financeira dos recursos temporais está na base da definição vigente sobre o trabalho. A relação entre tempo e trabalho fez com que a vida fosse depurada de todos os seus elementos disfuncionais e se fundamentasse na separação entre tempo de trabalho e tempo de não-trabalho, sendo este último continuamente - e cada vez mais intensamente - assediado pelos imperativos capitalistas. A tendência é minimizar o tempo do não-trabalho ou racioná-lo austeramente, já que estes momentos livres são interpretados como improdutivos (BATISTA et al., 2013, p. 33).

A citação anterior pode nos trazer à lembrança os momentos em que consideramos que não estamos aproveitando o tempo ou fazendo algo produtivo com ele, é possível termos a sensação de necessidade de utilizar nossas horas sempre com coisas que signifiquem algum tipo de produção útil. Porém, esta pode ser apenas uma visão vendida pelo capitalismo, como afirma Batista et al. (2013).

Em função da atual importância da informação na nossa sociedade, Montes e Herzog (2005) observam que há uma constante preocupação em redução do tempo para desenvolver as atividades, o considerando um bem de consumo. Para as autoras é possível dizer que se vive em um mundo de antecipação, o qual o passado é virtual e o futuro é vivido no presente, de modo antecipado. Neste sentido, só existe o presente:

Esse presente instantâneo, que não pressupõe história. Uma imagem sem conexão com uma cena anterior e que é antecipada a fim de proteger o sujeito do engano e da dúvida. Neste contexto, o número de deprimidos cresce na medida em que, diante da exigência de velocidade e dinamismo, não é raro o sujeito considerar-se ineficiente". (MONTES; HERZOG, 2005, p. 57).

Isso explicaria, para as autoras supracitadas, a frequente queixa de perda de controle sobre nossas próprias vidas, em que "todos devem ser dinâmicos, ágeis, capazes de mudar a própria vida a todo o momento" (MONTES; HERZOG, 2005, p. 58). Podemos considerar, que esta é uma consequência da sociedade da informação, a qual o ritmo relacionado à informação é mais acelerado e as responsabilidades de mudança da vida de cada um é de sua própria responsabilidade, sem receber o apoio adequado. 
A sensação de que o tempo está passando mais rápido é também debatida em revistas de lazer, como a Super Interessante. E de acordo com o autor de uma das matérias a respeito, $\operatorname{Brum}(2018$, p.1):

\begin{abstract}
A psicologia e a neurociência se uniram para entender esse fenômeno. Conclusão: você não está errado em achar a vida mais rápida. Embora o tempo seja o mesmo para todos, cada pessoa percebe sua passagem de forma diferente. E a primeira explicação para isso não traz consolo: os dias parecem passar mais rápido porque você está ficando velho.
\end{abstract}

O autor supracitado, também afirma que há outras teorias para essa sensação. E uma delas é a rotina voltada para a tecnologia:

Com smartphones e computadores à disposição o dia inteiro, sempre há um e-mail a mais para responder, uma planilha a mais para preencher, um lembrete extra para o dia seguinte, e o cotidiano de trabalho passa a invadir até mesmo as horas antes dedicadas ao lazer. Quando você encontra tempo para descansar de verdade, surge um novo tipo de ansiedade: a montanha de opções de lazer. A internet e o smartphone extinguiram o tédio. Hoje, sempre há mais opções de divertimento do que tempo disponível para consumi-las, e o mal-estar da falta de tempo para conferir tudo persiste (BRUM, 2018, p. 1).

Neste sentido, o relatório "2019 Global Digital” (WE ARE SOCIAL; HOOTSUITE, 2018), apresenta dados sobre a relação das pessoas com o uso da internet, celulares e redes sociais. O relatório aponta que mais de 5 bilhões, dos 7,6 bilhões do total populacional, hoje possuem acesso à internet e quase 4 bilhões são usuários ativos de redes sociais. $\mathrm{O}$ tempo médio o qual uma pessoa fica conectada está em 6 horas diárias, no entanto, este número é variável de acordo com o país. No Brasil, a média ultrapassa as 9h diárias de uso da internet, ficando em segundo lugar entre os países que mais tempo conectados, ficando atrás apenas das Filipinas. Considerando apenas acesso com aparelhos móveis, os brasileiros estão em terceiro lugar, utilizando por uma média de 4 horas e 45 minutos diários, atrás da Tailândia e das Filipinas. Ainda no Brasil, 70\% das pessoas utilizam internet, sendo que a média mundial está em 57\%. Nos Estados Unidos este índice sobe para 99\%.

O uso das redes sociais e da internet de modo geral ocupa parte do dia de muitas pessoas, seja para trabalho, lazer ou estudos. É importante destacar que ainda há boa parte da 
população excluída do acesso à informação, então quando se trata do excesso de informação refere-se a uma parcela das pessoas que utilizam intensivamente as tecnologias.

O excesso de informação pode fazer com que as pessoas se sintam sobrecarregadas, mas é importante considerar que a informação não exige que as pessoas a consumam, a questão está no hábito de consumi-la que pode colocar a pessoa em uma posição desconfortável, ou seja, o consumo excessivo é que pode representar um problema (JOHNSON, 2012). No entanto, pode não ser fácil dosar a quantidade de informação que consumimos, considerando a disponibilidade atual e as facilidades de acessá-la. Isso pode fazer com que os momentos de lazer sejam ocupados consumindo informação desnecessária.

Vive-se em uma realidade a qual há a busca pelo fazer mais em menos tempo e assim livros e revistas vendem dicas de como aumentar a produtividade. Textos repletos de orientações nesse sentido dizem algo como "apostar em novas formas de produzir e contar com o auxílio da tecnologia: esses são os caminhos de como produzir mais em menos tempo" (DIGITAL NETSCAN, 2017). Seguindo este panorama as pessoas aproximam-se de robôs em que precisam fazer e fazer, sempre correndo contra o passar do tempo, como se este fosse um inimigo a ser superado. Como se a mente humana devesse ser mais inteligente do que o tempo, para vencê-lo. Esta parece ser uma das lutas dos seres humanos e aonde perdemos e podemos nos tornar mais ansiosos pelo fazer em menos tempo.

\section{CONSIDERAÇÕES FINAIS}

Ocupamos o nosso tempo hoje com diversos afazeres relacionados à informação e não mais com estruturas apenas relacionadas aos hábitos religiosos ou de sobrevivência. Nossas necessidades mudaram e a informação passou a fazer parte da nossa vida de modo tão invasivo que algumas vezes sentimos dificuldade em nos afastar do universo informacional. Viver na sociedade da informação pode nos fazer seres humanos cheios de atividades relacionadas à informação que ocupam muitas horas diárias. Sem tempo para vivenciar o aqui e o agora e sobrecarregados de informação, podemos acreditar que o tempo passa mais rápido, afinal, há menos momentos para contemplá-lo.

Vimos ao longo do texto que a percepção do tempo mudou e não poderia ser diferente, uma vez que a sociedade se transformou e os modos de vida das pessoas também. A sobrecarga de informação e a sensação de falta de tempo faz com que surjam movimento a 
fim de recuperar o que foi perdido, um modo de viver mais leve, menos corrido e sobrecarregado.

Independente das sensações individuais de como o tempo passa, de fato a relação entre as pessoas e o tempo foi alterada ao longo dos anos e das mudanças sociais. Hoje o tempo está no relógio e pouco dele sobra para o lazer, muitas vezes organizado metodicamente. Observou-se que a preocupação com o passar veloz do tempo não é questão apenas das nossas gerações, mas algo que perturba o ser humano há séculos e que não somos capazes de controlar essa situação.

Além das percepções sobre o tempo há que se considerar que ocupar demais nossos dias com trabalho, e o acesso à informação articulado com o uso em excesso de smartphones, faz com que sobre menos tempo livre para o ócio, para momentos em que não se faz nada que deva ser produtivo ou relacionado às tecnologias e isso pode trazer ainda mais a sensação de que o tempo passa mais rápido, porque ocupamos boa parte dele com muitas ocupações e com muita informação. Ao longo dos anos as rotinas das pessoas se alteraram, logo seus sentimentos quanto ao tempo disponível diante do excesso de informação a que estamos submetidos.

\section{REFERÊNCIAS}

ASAD, Talal. Pensando sobre tradição, religião e política no Egito contemporâneo. Política \& Sociedade: revista de sociologia política, Florianópolis, v. 16, n. 36, p. 347-402, maio/ago. 2017. Disponível em: https://periodicos.ufsc.br/index.php/politica/article/view/21757984.2017v16n36p347. Acesso em: 29 mar. 2019.

BATISTA, Mariana Klein et al. Slow movement: trabalho e experimentação do tempo na vida líquido-moderna. Psicologia \& Sociedade, Belo Horizonte, v. 25, n. 1, p. 30-39, 2013. Disponível em: http://www.scielo.br/scielo.php?script=sci_arttext\&pid=S010271822013000100005\&lng=en\&nrm=iso. Acesso em: 29 mar. 2019.

BAUMAN, Zygmunt. Modernidade líquida. Rio de Janeiro: Jorge Zahar Ed., 2001.

BAWDEN, David; HOLTHAM, Clive; COURTNEY, Nigel. Perspectives on information overload. Aslib Proceedings, v. 51, n. 8, p. 249-255, set. 1999. Disponível em: http://www.emeraldinsight.com/doi/abs/10.1108/EUM0000000006984?journalCode=ap. Acesso em: 14 ago. 2019. 
BODY-GENDROT, Sophie. Uma vida privada francesa segundo modelo americano. In: PROTS, Antoine; VINCENT, Gérard (Org.). História da vida privada, 5: da Primeira Guerra a nossos dias. São Paulo: Companhia das Letras, 2001. Cap. 3. p. 529-580.

BRUM, Maurício. O tempo está passando mais rápido? Super interessante. S.1., 06 jun. 2018. Disponível em: https://super.abril.com.br/comportamento/o-tempo-esta-passando-maisrapido/. Acesso em: 29 mar. 2019.

CARVALHO, Rubens Moreira Rodrigues de. Cittaslow: vida lenta e sustentabilidade nas cidades do bem viver. Periódico Técnico e Científico Cidades Verdes, Tupã, v. 3, n. 7, p. 37-52, ago. 2015. Disponível em:

https://www.amigosdanatureza.org.br/publicacoes/index.php/cidades_verdes/article/view/975. Acesso em: 29 mar. 2019.

CASTELLS, Manuel. A sociedade em rede. São Paulo: Paz e Terra, 2006. V.1.

DIGITAL NETSCAN. Como produzir mais em menos tempo? 20 dez. 2017. Disponível em: https://netscandigital.com/blog/como-produzir-mais-em-menos-tempo/. Acesso em: 29 mar. 2019.

JOHNSON, Clay A. A dieta da informação: uma defesa do consumo consciente. São Paulo: Novatec, 2012.

LE GOFF, Jacques. Para um novo conceito de Idade Média: tempo, trabalho e cultura no Ocidente. Lisboa: Estampa, 1993.

LECCARDI, Carmen. Para um novo significado do futuro: mudança social, jovens e tempo. Tempo social, São Paulo, v. 17, n. 2, p. 35-57, nov. 2005. Disponível em: http://www.scielo.br/scielo.php?script=sci_arttext\&pid=S0103$20702005000200003 \& \operatorname{lng}=e n \& n r m=i s o$. Acesso em: 29 mar. 2019.

MAFFESOLI, Michel. Comunidade de destino. Horizontes antropológicos, Porto Alegre, v. 12, n. 25, p. 273-283, jun. 2006. Disponível em:

http://www.scielo.br/scielo.php?script=sci_arttext\&pid=S0104-

$71832006000100014 \& \operatorname{lng}=e n \& n r m=i s o$. Acesso em: 29 mar. 2019.

MATTELART, Armand. Sociedade do conhecimento e controle da informação e da comunicação. In: Encontro Latino de Economia Política da Informação, Comunicação e Cultura, 5., 2005, Salvador. Anais [...]. UFBA, 2005. p. 1-22. Disponível em: http://www.gepicc.ufba.br/enlepicc/ArmandMattelartPortugues.pdf. Acesso em: 29 mar. 2019.

MONTES, Fernanda Ferreira; HERZOG, Regina. A relação do sujeito com o tempo na atualidade. Pulsional: Revista de Psicanálise, s.1., v. 28, n. 184, p. 49-59, dez. 2005. Disponível em: http://www.editoraescuta.com.br/pulsional/184_05.pdf. Acesso em: 15 out. 2018.

QUINTANA, Mario. Esconderijos do tempo. Objetiva: Rio de Janeiro, 2013. 
RÉGNIER-BOHLER, Danielle. Ficções: exploração de uma literatura. In: DUBY, Georges (Org.). História da vida privada, 2: da Europa feudal à Renascença. São Paulo: Companhia das Letras, 2004. Cap. 3. p. 311-392.

RUST, Leandro Duarte. Jacques Le Goff e as representações do tempo na Idade Média.

Revista de História e Estudos Culturais, s.1., v. 5, n. 2, p. 01-19, abr. 2008. Disponível em: http://www.revistafenix.pro.br/vol15JDuarte.php. Acesso em: 29 mar. 2019.

WE ARE SOCIAL; HOOTSUITE. 2018 Global Digital. S.I: S.n., 2019. 221 p. Disponível em: https://wearesocial.com/global-digital-report-2019. Acesso em: 20 mar. 2020.

WERTHEIN, Jorge. A sociedade da informação e seus desafios. Ciência da Informação, s.l., v. 29, n. 2, p. 71-77, 2000. Disponível em:

http://www.scielo.br/scielo.php?script=sci_arttext\&pid=S0100-

19652000000200009\&lng=pt\&tlng=p. Acesso em: 29 mar. 2019. 